\title{
Teaching Students to Think - Faculty Recommendations for Teaching Evaluations Employing Automated Content Analysis
}

\author{
Nitza Davidovitch ${ }^{1} \&$ Eyal Eckhaus $^{1}$ \\ ${ }^{1}$ Head of Academic Quality and Assessment, Head of Teacher Training Program, Ariel University, Israel \\ Correspondence: Nitza Davidovitch, Ariel University, Ariel, Israel.
}

Received: March 13, 2018

Accepted: May 5, 2018

Online Published: May 10, 2019

doi:10.5430/ijhe.v8n3p83

URL: https://doi.org/10.5430/ijhe.v8n3p83

\begin{abstract}
Many studies have been conducted on teaching evaluations completed by students and on myths and facts concerning these evaluations performed by students at academic institutions. The current study is unique in examining the meaning of teaching evaluations as perceived by academic faculty members in Israel through direct questions, with an emphasis on faculty's recommendations for improving the evaluations to make students' comments meaningful for enhancing and advancing their teaching. The perception of evaluations is unique too. Evaluations are part of faculty's learning outputs in their courses, with the aim being for graduates of academic systems to have the ability to provide objective and fair assessments.

One hundred seventy seven questionnaires were gathered from senior faculty at several academic institutions. Qualitative and statistical research tools were used in order to form a model that expresses the negative implications as seen by faculty members and alternatives for measuring the performance of faculty in academic teaching. The research findings indicate that lecturers note "professional" alternatives and see teaching evaluations as a populist rather than a professional tool. Moreover, although the lecturers gauge the damage caused to them as a result of student evaluations, where the enormous damage caused to them is disproportionate to the number of respondents, and although faculty members believe that student evaluations are untrustworthy, students' opinions on the courses are important. Their recommendation is that the evaluation should be a tool for teaching how to perform evaluations and convey criticism - and in this field not much has been done in academic institutions, if at all. Academia sees evaluations as a technical matter, a means of satisfying students by letting them express their opinions and of giving students a feeling that the system is attentive to their voice, to their views.

Indeed, students' voice is important to the lecturers - their opinions of teaching are important - and that is precisely why action should be taken to render these evaluations fair. Students should understand the power of the words that express their evaluation of the lecturers. This point of view is a first of its kind, where academic faculty members support students' opinions and provide recommendations aimed at their improvement.
\end{abstract}

Keywords: teaching evaluations, myths, lecturers, assessment

\section{Introduction}

The status of evaluation forms has gained significance in the past decade and they have been transformed from an evaluation tool that provides recommendations for improvement to a tool whose results have significant consequences for academic careers - tenure, promotion, and appointments (Ehie \& Kararthanos, 1994; Harrison et al., 2004; Smith et al., 2004; Williams \& Ceci, 1997). These aspects have inevitable impacts on salaries, perceived prestige, and possibilities for career development. Evaluation results are awarded considerable significance and constitute measures utilized by superiors. The considerable dominance of evaluation forms (Chandler, 1978) dictates and determines the lecturer's career development track to a not insignificant degree.

These implications have turned the forms into a source of much criticism by the academic faculty (Smith et al., 2008) and an object of many studies that seek to examine their reliability and validity, as well as to what degree students' perceptions should be given the power to affect the career of academics. Opinions are divided in two - supporters and objectors. Some claim that this dispute is the most significant in all research on teaching (Kulik, 2001).

Despite the dispute, everyone agrees about the significance of promoting "efficient teaching" and improving the quality of teaching (National Survey, 2002). Academic institutions develop policy and criteria with the purpose of 
encouraging, rewarding, and measuring "good teaching" (Ballantyne et al., 2000). Hence, the dispute is not about the need for control rather about how it should be carried out and its efficacy.

The purpose of the current study is to examine the recommendations of academic faculty members in Israel as to how students' evaluations of teaching in courses can be improved so that students' comments will have significance for improving and advancing faculty teaching. This, based on a perception of evaluations as part of the learning output of faculty members in their courses, with the goal of instilling in graduates of academic systems the ability to provide objective and fair assessments and criticism.

\section{Preface}

Forms for evaluating lecturers were first introduced to academia at the beginning of the previous century, but their status and significance increased mainly from the 1970s (Hativa, 2008). Over the years, the forms received the status of an efficient and inexpensive tool constituting a way of assessing the efficacy of teaching and a means of deriving operative conclusions regarding improvement of teaching quality and assessing lecturers' performance. Use of the forms is very popular in the United States and Canada, which see the great importance of transforming teaching into a professional career and setting strict standards of knowledge and skill for teaching (Hativa, 2003; Hativa, 2002). Evaluation forms are perceived as a means of realizing these goals and are leading European countries to embrace the evaluation method, despite the disputes regarding the forms as a valid measure for reaching applied decisions (Reinderman \& Schofield, 2001).

In the first years of their use, evaluation tools had no far-reaching implications, however over the years the status of teaching evaluations has grown and they have been transformed from a mere evaluation tool that provides recommendations for improvement to a tool whose results have significant consequences for academic careers academic tenure, promotions, and appointments (Ehie \& Kararthanos, 1994; Harrison et al., 2004; Smith et al., 2004; Williams \& Ceci, 1997).

These aspects have inevitable impacts on salaries, perceived prestige, and possibilities for career development. Evaluation results receive considerable significance and provide measures for superiors. The large dominance of evaluation forms dictates and determines the lecturer's career development track to a not insignificant degree.

These implications have turned the forms into a source of much criticism by the academic faculty (Smith et al., 2008) and an object of many studies that seek to examine the reliability and validity of the evaluation forms, to what degree students' perceptions should be given power to affect the career of academics. Opinions are divided in two supporters and objectors. Some claim that this dispute is the most significant dispute in all research on teaching.

On one hand, some see the very existence of the form as a judgmental means that harms the lecturer's academic status, puts him or her at a disadvantage, and is forced on him (Avdor, 2006). Advocates of this approach feel that they are expected to "provide the merchandise" for the students, and in return the latter give them credit points. This point of view often stems from a lack of dialogue between the lecturers and their superiors, among the lecturers, and between lecturers and students (ibid.). These are countered by those who support the forms and recognize the significance of the evaluations as a means of advancing and improving the quality of teaching as well as the satisfaction of the students-consumers (Marsh, 1987; Marsh \& Roche, 1994; Ramsden, 1991).

Despite the dispute, everyone agrees on the significance of promoting "efficient teaching" and improving the quality of teaching (National Survey, 2002). Academic institutions develop policy and criteria with the purpose of encouraging, rewarding, and measuring "good teaching" (Ballantyne et al., 2000). The dispute is not about the need for control but rather about how it should be carried out and its degree of efficacy. The question is whether the academic system, which recognizes the significance of students' teaching evaluation results, indeed also considers how students should be taught skills of assessment and measurement. How can students' assessment skills be improved so that their comments will be meaningful for improving and advancing faculty teaching. The perspective regarding how evaluations are perceived is unique too, where evaluations are perceived are part of the faculty's learning outputs in their courses, with the aim being that graduates of academic systems should have the ability to provide objective and fair assessments.

\subsection{The CHE: Academic Institutions will be Required to Meet Standards for Improving Teaching}

The Council for Higher Education (CHE) encourages use of these evaluations, and as of the 2010/11 school year they constitute part of the quality assessment report submitted to the CHE by academic institutions, intended for the use of the international committees that inspect the quality assessment process in the various departments. 
Completion of the forms in the institutions was carried out in the past by writing on printed forms distributed to students in one of the last classes in the semester. Since then, students have transitioned to completing surveys online.

Despite efforts invested in marketing and in promoting students' motivation to complete the online teaching survey, participation rates were very low (25\%-30\%).

In 2015 the findings of a survey on teaching quality and evaluation at institutions of higher education were formulated - most institutions of higher education invest efforts in improving the quality of teaching.

According to a decision of the CHE plenum, all government-funded universities and colleges must meet a list of criteria that require them to take steps to improve the quality of teaching.

The decision determines that all government-funded academic institutions will be required to maintain an official apparatus in charge of carrying out the mandatory steps: holding professional training sessions on teaching for new faculty on all levels, including external teachers and teaching assistants; administering evaluation surveys of teaching in each semester and in all courses given at the institution; providing the findings of the surveys and the students' comments to all lecturers evaluated and to their superiors, while stating their relative rating in the department and in the institution; maintaining a system for dealing with lecturers for whom the results of the teaching surveys deviate from the standard (in both directions); providing an accessible and public system for accepting students' complaints regarding teaching and handling these complaints; publicizing and distributing detailed syllabi for all courses as well as rules concerning requirements for courses and how grades are determined; transparency in faculty schedules and lecturer availability; and support for faculty with all matters related to teaching technologies.

The significance of student evaluations of teaching is growing in the capitalist academic world, in the sense of what do the clients have to say? Very little research attention has been given to the meaning of teaching surveys in the current era, particularly in a generation when people write without stopping to think, where everything is exposed for all to see - digital and online.

\subsection{The "Response to Needs" Approach - Learner-Centered}

Paradigmatic transformations have occurred in Israel's system of higher education (Mizrachi, 1994), indicating that the face of higher education has changed with the changes, reflecting the different and preferential treatment of the needs of science, society, and the individual (Yaoz \& Iram, 1987). The changes are, to a large degree, the product of developments in educational thought in general, higher education in particular, and shifts in Israeli society as manifested in higher education. The effects of "progressive" trends in the philosophy of education, which demand that the learners be placed in the center, have gradually intensified in Israel. These trends have been translated into the language of education, in all educational systems, in the form of excess individualization (Chen, 1998; Iram, 1978).

Higher education is measured from this perspective of responding to needs (Miller, 1990). This approach is compatible with the aims of institutions of higher education: research and teaching, which constitutes a service for the community of learners (Mizrachi, 1994).

Until World War II, the main role of the higher education system was to nurture the elite. This system served as a mirror of the elite and as an instrument for preserving the existing social order. The change that occurred is that higher education, which could previously be defined as an opportunity reserved for the privileged few, became a universal right and even a civil duty. From the latter half of the $20^{\text {th }}$ century we witnessed a phenomenon of massification of higher education, when higher education was expanded from the elite to the masses, namely, a transformation was evident in the composition of the student population, their motives for studying, and their study habits - a new reality (Davidovitch, 2014).

Hence, one of the challenges encountered in this new reality was to preserve quality: in research, in teaching.

Following the transformation of higher education to a system that is accessible by the masses we are witnessing phenomena such as: large classes, a diminishing of the humanities and the natural sciences, degree commercialization, degree inflation, grade inflation and superficial demands, disrespect for research values, involvement of workplaces, studies motivated by the desire to acquire money and status, "advanced" degrees for everyone (with no thesis), plagiarism, and more. These are phenomena that affect academic teaching processes, and a new profile of learners has emerged, who are now "consumers". As a result, faculty members are currently skeptical regarding the results of teaching surveys that indicate students' satisfaction with faculty teaching. 
In summary, the research literature indicates that in recent years fissures have emerged in academia - forming a backdrop for the faculty's gradually increasing lack of confidence in the results of teaching surveys reflecting students' satisfaction with faculty teaching.

This is the background for examining the effect of faculty's frustration with student evaluations of teaching, on one hand, and the understanding that in the current times it is important to hear the students, the "clients".

In the desire to approach the issue from both angles, in the current study we examined the recommendations of faculty on how to improve students' assessments so that their comments will have meaning for faculty members, with the purpose of improving and advancing teaching and learning processes in courses. The very existence of these faculty recommendations was found to reflect the perception of evaluations as part of faculty's learning output in their courses, with the aim being for graduates of academic systems to be capable of providing objective and fair assessments.

Academic teaching has undergone deep transitions throughout the world and therefore it is important to examine ways of properly and fairly evaluating the quality of teaching in academia, and teaching should definitely constitute a factor in processes of appointment and promotion - the question is how?

\subsection{Evaluation of Lecturers by Students - Educating on How to Provide Assessments and Criticism}

In faculty members' perception, numerical rankings given as part of students' evaluations of teaching would be more meaningful if students would also note their assessment verbally. Therefore, in order for the verbal part of the evaluation to be positive, students must be educated and must be taught to think before completing assessments. Faculty members note that assessments of faculty should not be given absent-mindedly, without teaching students how to perform assessments and to express criticism.

Faculty see assessments as one of the lecturer's learning outcomes generated by the course.

According to this approach, assessments are an integral part of planning a course in the learning-focused approach, and they help form a dialogue between academic faculty and students and lead to compatibility between the learning results (course goals) and the teaching methods and assessment goals (Davidovitch, 2013, 2016).

Learning outcomes are statements by a lecturer or a group of lecturers that specify what students will know or will be capable of doing as a result of the learning activity. Outcomes are usually expressed as knowledge, proficiencies, or views.

Learning outcomes are declarations regarding what students are expected to know, understand, and/or be capable of demonstrating by the end of the learning process.

The research literature on assessments does not refer to this innovative approach that sees assessments as a challenge embodied by the formulation of learning goals.

\subsection{Planning a Course in the "Learning Outcomes" Method - What is it?}

At the end of the course students are not asked: What did you learn in order to complete the course? But rather: What do you know and what can you do now that you couldn't do before you took this course? Therefore, the first step in planning a course is defining teaching goals: What will the student know and be capable of doing in general by the end of the course?

\subsection{How to Plan a Course in the Learning Outcomes Based Approach?}

- Focus on the student's point of view.

- Focus on outcomes. Learning outcomes express what students are expected to do by the end of the learning period.

- Outcomes are defined clearly and unequivocally.

- Outcomes determine the contents of the study program, the structure of the program, the teaching methods, the assessment process, and the schedule. Learning outcomes also provide a framework for assessing the study program.

\subsection{Example: Developing a Course in Stages in STEM Disciplines}

Stage 1: Formulating student-focused overall goals

\section{- What do you expect the graduate to know and to be able to do?}

- What do you expect the student to know and to be able to do by the end of the course/unit (with regard to skills, knowledge, proficiencies, conceptions, values)? 
- What effect would you like this course to have on students' life by the end of the course? In a few years?

- What are the practical expectations of the course graduates?

According to the STEM approach, possible goals are by the end of the course students will have the capacity of: assessment and criticism; understanding professional and ethical responsibility; ability to understand the wide education required and to recognize the need and ability to engage in learning throughout life.

This is a holistic approach (Nisanholtz-Ganot \& Davidovitch, 2018) - hence, after the course goals are formulated by the lecturer, the lecturer shall select the assessment methods (for measuring the achievability of the teaching goals) and will determine standards for evaluating performance - How can the student demonstrate that he knows and is capable of doing what was formulated in the goals and the teaching methods. For example, an open-ended exam (rather than a closed-end multi-choice exam - so that students will acquire the art of written expression; or choosing peer assessment, which includes imparting evaluation and critical skills as well as ethical and collegial responsibility.

In summary, the uniqueness of the teaching method based on learning outcomes begins with identifying the learning goals of the course rather than the material and contents of the course.

How are goals identified? The lecturer asks himself: What should students know and be capable of doing by the end of the course? The lecturer chooses the evaluation methods and determines criteria for assessing performance: according to the goals, as well as selecting the teaching method according to the goals: What is the best way for me to teach as an lecturer in order to achieve the learning goals: both regarding the material that will be included in the course and regarding the teaching strategy, as well as assessment and critical skills that we wish to instill in students, based on the conception of assessment as a shaping and significant factor.

This approach, which sees assessments as a means in higher education, as part of the learning outputs, is also part of the SWOT model.

The goal: Lecturers (as well as students) strive to improve students' performance on assignments and to evaluate performance in a way that will advance students' learning.

The method: Use of teaching strategies based on giving students feedback on performance of an assignment during the course. The feedback is given by students-peers, by the lecturer, and through class discussions.

This type of teaching is based on the SWOT model (Strengths, Weaknesses, Opportunities, Threats).

Embracing the model as an evaluation method in academic courses

The SWOT model refers to the demands of the academic course and includes (Davidovitch \& Levy, 2017):

- Strengths - Identifying and diagnosing strengths, abilities, and positive situations concerning the assignment given, with the aim of enabling students to achieve their goals;

- Weaknesses - Identifying and diagnosing inabilities and situations capable of preventing students from achieving their desired goals;

- Opportunities - Identifying and diagnosing factors and situations that can help students achieve their goals but have not yet been utilized by them in the outcome presented;

- In addition, Treatments - Presenting operative suggestions for necessary improvement, as evident in weaknesses and/or opportunities not utilized by students.

Based on previous studies (Davidovitch, 2013, 2017), the current study sees evaluations given by students as part of faculty's learning output in their courses.

\section{The hypotheses}

1. Providing textual content in students' evaluations of lecturers' teaching will have a positive effect in the form of higher scores in the evaluations.

H1. STUDENT positively affects TEXT

H2. TEXT positively affect SCOREPOS

2. Teaching students to think before completing evaluations of lecturers, will result in more positive contents.

H3. STUDENT positively affects THINK

H4. THINK positively affects THINKPOS 


\section{Methodology}

\subsection{Initial Sample}

Surveys were distributed online using Google Docs to the senior faculty members of seven academic institutions. One hundred seventy seven completed questionnaires were collected, divided as follows. Ariel University (88), Ben-Gurion University (20), Emek Yezreel Academic College (19), 7 respondents were divided between four other institutions, and the rest did not mention their affiliation. Gender wise, $49.4 \%$ of the respondents were females and $50.6 \%$ males. Respondents' age ranged from 22-39 (17.1\%), 40-49 (40.8\%), and 50+ (42.1\%).

The survey included four open-ended questions: "Do you think the teaching evaluation format should change, and how?", "In your opinion, are there alternatives for the teaching evaluation, in order to assess teaching? What are they?", "How do you think the teaching evaluations cause harm?", "What is the value of the teaching evaluations?", along with demographic questions.

\subsection{Survey Analysis}

Structural Equation Modeling (SEM) was used to test the model's goodness-of-fit (Eckhaus, 2019; Eckhaus \& Sheaffer, 2018a). Model fit was estimated using CFI, RMSEA, and minimum discrepancy, divided by their degrees of freedom (CMIN / DF). Values of CFI, NFI, and TLI above .9 are considered acceptable (Hinz et al., 2017), the ratio CMIN / DF should be as small as possible (ibid.); typically, lower than 3 is considered a good fit. RMSEA should be .06 or smaller (Hu \& Bentler, 1999).

\subsection{Content Analysis}

We employed a mixed methods design, with both quantitative and qualitative analysis, which provides a better understanding of the research problem (Ghasempour, Bakar, \& Jahanshahloo, 2014).

\subsection{Manual Classification}

Initially, we manually reviewed all the respondents' texts and identified major themes, as follows. STUDENT refers to students. TEXT - the open questions/qualitative feedback that the students write in their evaluations of the lecturers. THINK - thinking before writing and a serious approach to the evaluations. SCORE - the grades and students' exams. POSITIVE - refers to positive implications, such as improving, contributing, and motivating.

Next, we constructed interaction variables: TEXTPOS - positivity of the textual content the student writes in the evaluation. SCOREPOS - positivity regarding the scores the students give in the evaluations, i.e., good scores in evaluations of lecturers.

\subsection{The Following are Quotes from Faculty Statements}

Regarding the need to teach students to focus on what is before them faculty state that "comments are not to the point" or "sometimes the evaluation is not relevant". Another faculty member added that "the evaluations are often not to the point and are insulting". Another faculty member expanded on the consequences of this: "Comments that are not to the point or are insulting create an unpleasant feeling that obviously affects energies".

In addition, faculty members state that "students who do not attend give evaluations" and that "there is no correlation between students who attended the course and those who complete the forms". This has the effect, as stated by faculty members, that "at present the evaluations are a very untrustworthy evaluation tool" and that "at present evaluations do not give a true picture of what is happening in the course and it is necessary to think of an alternative method".

In contrast, when faculty members were asked to find alternative solutions, several ideas were raised, such as "to interview several students in a focus group", "holding interviews with selected students during the semester", "meeting... with students at the end of the semester in order to hear about the teaching personnel", or even "ongoing and direct contact with the students themselves". Namely, solutions that require students to respond judiciously and that do not enable irresponsible completion of evaluations, which might ultimately hurt the lecturer unjustifiably. As described by a faculty member, "quite a few complain unfoundedly although they did not attend/participate/make an effort during classes".

In summary, the problem was well described by one of the survey respondents, who described himself as "a former undergraduate student here" and claimed: "I understand the thinking of students here. Most of them want to receive as much information as possible about exams and to have the teaching assistant only solve exams. They are not interested in understanding the study material or how to approach the exercises". This statement clarifies the essence and depth of the problem; in an institution that is supposed to educate and to develop knowledge, students are not 
engaged in learning. This problem is the Achilles heel of the academic world, whose prestige is gradually diminishing versus organizations that promise their students a profession. The same approach reflecting disinterest in that which is before them is evident in the evaluations, together with results that might be harmful to lecturers.

\subsection{Automated Text Classification}

We employed TEXTIMUS, a software that supports text mining and automated content analysis (Eckhaus \& Ben-Hador, 2017, 2018). In the first step, we generated n-gram frequencies. N-gram refers to a contiguous sequence of $\mathrm{n}$ words from a given sequence of text (Davidovitch \& Eckhaus, 2018b; Toosinezhad, Mohamadpoor, \& Tabatabaee Malazi, 2018). For instance, when applying n-gram to the sentence "happiness may be enriched and sustained" (Eckhaus \& Sheaffer, 2018b), unigram represents collections of single words and bigram each pair of words (such as 'Happiness may,' 'may be,' 'be enriched,' etc.). Next, we made use of the 'Bag-of-Words' (BoW) technique (Davidovitch \& Eckhaus, 2018a; Eckhaus, 2018; Eckhaus \& Davidovitch, 2018a, 2018b), known as the most common method for text analysis based on Natural Language Processing (NLP). This technique is based on the concept that documents are represented as a collection of words, regardless of grammar and order. A set of keywords is explored in all the documents, with values weighted according to whether the word appears in a document, or the number of times it appears (Davidovitch \& Eckhaus, 2018b). Therefore, we analyzed the frequency of all words in the set of texts, and compiled groups of the most frequent words employed for each of the research variables. Similar to studies that employed BoW in organizational contexts (Eckhaus, 2016; Eckhaus \& Sheaffer, 2018c; Eckhaus, Taussig, \& Ben-Hador, 2018; Eckhaus, Weber, Koppel, \& Spiegel, 2018), we then summed the words' occurrences to create the variables.

\section{Results}

The correlations, means, and standard deviations between the research variables are presented in Table 1 .

Table 1. Correlation matrix: Means, SD

\begin{tabular}{|c|c|c|c|c|c|}
\hline & STUDENT & THINK & $T E X T$ & TEXTPOS & SCOREPOS \\
\hline STUDENT & - & & & & \\
\hline THINK & $.30 * * *$ & - & & & \\
\hline TEXT & $.29 * * *$ & .09 & - & & \\
\hline TEXTPOS & $.23^{* *}$ & $.21^{* *}$ & $.54 * * *$ & - & \\
\hline SCOREPOS & $.38 * *$ & .01 & $.19^{*}$ & $.31^{* * *}$ & - \\
\hline Mean & 1.81 & .10 & .46 & .67 & .78 \\
\hline SD & 1.97 & .41 & .86 & 3.1 & 2.67 \\
\hline
\end{tabular}

Demographic variables: Gender, institution type (university or college), age, and seniority in the institution (in years), were added to the interaction variables as control variables.

Figure 1 illustrates the model and the regressions' weights. The hypothesized model showed a very good fit: CMIN / $\mathrm{DF}=1.59, p>.05, \mathrm{CFI}=0.91$, RMSEA $=0.058$. All hypotheses were supported. STUDENT positively affected TEXT (H1), TEXT positively affected SCOREPOS (H2), STUDENT positively affected THINK (H3), THINK positively affected THINKPOS (H4). The demographic variables had no statistical significance. 


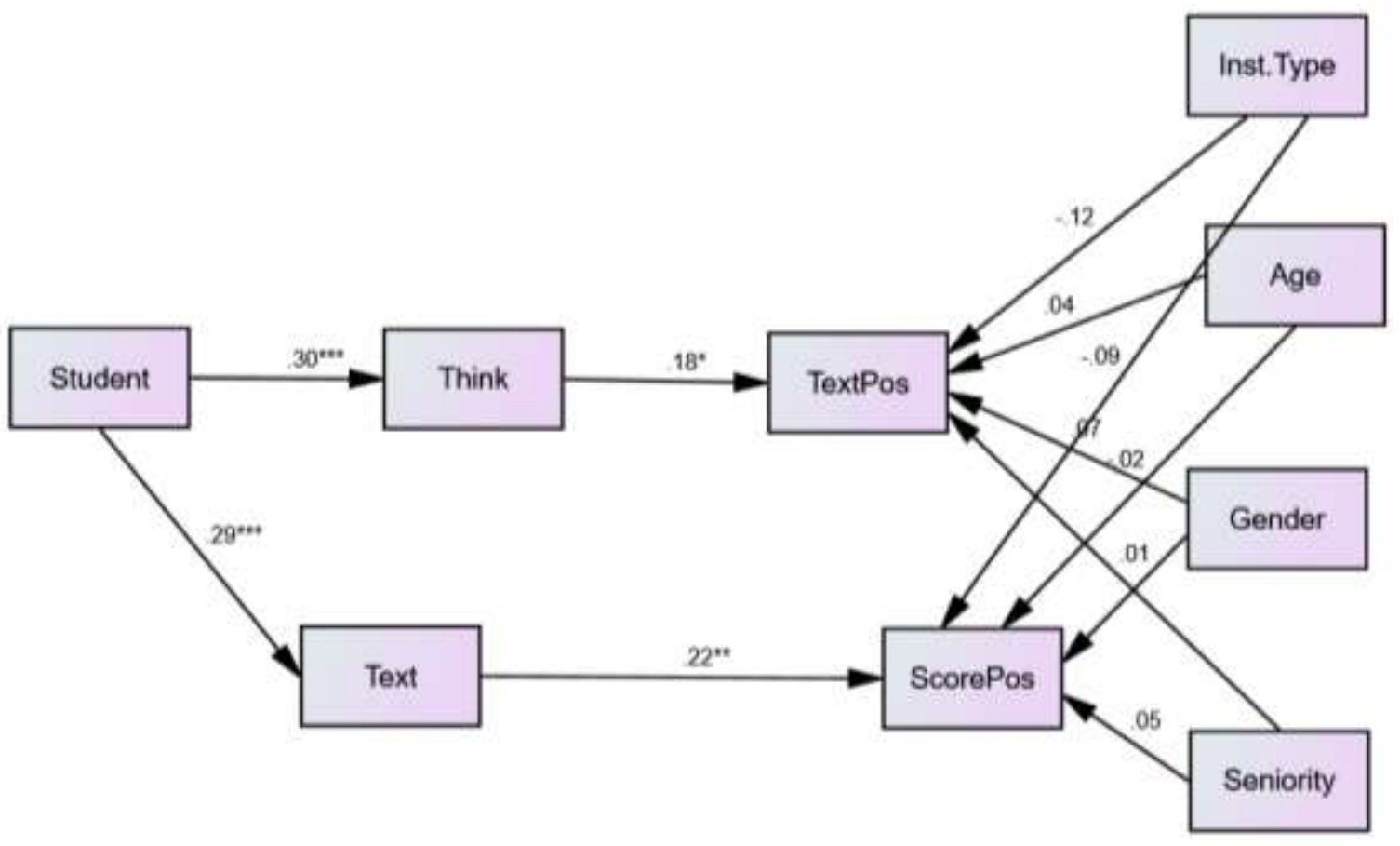

Figure 1. Model path and weights

The model proves that when students make an effort to think this affects their writing of positive comments. Moreover, there is more chance of good numerical rankings in the evaluation if it includes a verbal part.

According to these results, the clear recommendation indicated is as follows. In order to reach positive outcomes in the verbal part of the evaluation, students must be educated and taught to think before completing the evaluations. Completion should not take place without thinking and consideration. Once the approach is level-headed, it is necessary to make sure that there is a verbal part to complete in the evaluation and this will lead to higher rankings of lecturers.

\section{Conclusion and Discussion}

This study presents a new conception of academic teaching, one that sees evaluations as part of the learning outcomes of faculty members in their courses. Despite the potential sense of harm as a result of the evaluations, as we showed in previous studies, and recognizing the significance of students' opinions on the course, lecturers raise the significance of taking action to render these evaluations fair. Students must understand the power of the words that express their evaluation of the lecturers. This point of view is the first of its kind, with academic faculty supporting students' opinions and offering recommendations for their improvement.

In the learning outcomes view, planning the course begins with identifying the learning goals rather than the material and contents of the course. In order to identify the goals the lecturer must ask himself: What should students know and be capable of doing by the end of the course? Furthermore, he must choose the evaluation methods and standards for measuring the quality of performance. The teaching method will be selected according to the goals defined. The lecturer must choose the best teaching method for him as a lecturer, both with regard to the material to be included in the course and with regard to the teaching strategy, planning the schedule, and designing the syllabus. Perceiving the evaluation as an inseparable part of planning the course will make it possible for students to acquire evaluation and critical skills on the personal level.

The more knowledge becomes accessible, the more lecturers are required to bring added value to studies. This is not a simple requirement and it compels lecturers to think "outside the box" and to give up regular teaching patterns. It demands acquaintance with the students, readiness for change and to receive evaluations and criticism. In this way, a lecturer cannot come to class without holding a type of self-examination concerning the goals and means he intends to use. This involves considerable effort, however such an effort makes it possible for the lecturer to face the students 
with a true and honest answer to questions such as "What will I do with it in real life?" or "Why is it necessary to come to class?".

As perceived by the lecturers, evaluation and criticism are important values in the academic world, in the employment world - and in fact, in all areas of life. Evaluations enable lecturers to perform teaching activities capable of challenging this area.

\section{References}

Avdor, S. (2006). For whom and for what? Bias factors in evaluating teaching and courses at a college of education and the question of the procedure's contribution to those evaluated and to the organization. Dapim, 41, 10-37. [Hebrew]

Ballantyne, R., Borthwick, J. \& Packer, J. (2000). Beyond student evaluation of teaching: identifying and addressing academic staff development. Assessment \& Evaluation in Higher Education, 25(3), 221 - 236. https://doi.org/10.1080/713611430

Chandler, T. (1978). The questionable status of student evaluations of teaching. Teaching of Psychology, 5(3), $150-$ 152. https://doi.org/10.1207/s15328023top0503_12

Chen, D. (Ed.) (1998). The school of education towards the 2000s. Tel Aviv University. [Hebrew]

Davidovitch, N., \& Eckhaus, E. (2018a). Effect of faculty on research cooperation and Davidovitch, N. (2014). Academic research products - are they measurable? The case of Ariel University. European Journal of Educational Sciences, 2(1), 14-40. ISSN 2053-9746.

Davidovitch, N., \& Eckhaus, E. (2018a). Effect of faculty on research cooperation and publication: Employing natural language processing. Economics and Sociology, 11(4), 173-180. https://doi.org/10.14254/2071-789X.2018/11-4/11

Davidovitch, N., \& Eckhaus, E. (2018b). The influence of birth country on selection of conference destination-employing natural language processing. Higher Education Studies, 8(2), 92-96. https://doi.org/10.5539/hes.v8n2p92

Davidovitch, N. (2013). Learning-centered teaching and backward course design - From transferring knowledge to teaching skills. Journal of International Education Research, 9(4), 329-338. ISSN: 2158-0979. https://doi.org/10.19030/jier.v9i4.8084

Davidovitch, N., \& Shiller, Z. (2016). Skill-based teaching: Teaching robotics and mechatronics to mechanical engineers. American Journal of Engineering Education, 7(1), 29-36. https://doi.org/10.19030/ajee.v7i1.9683

Davidovitch, N., \& Levy, B. R. (2017). The Future Relevancy of University Institutions - Teaching and Learning Academic Studies in the Digital Era: Learning-centered Approach Vs. Teaching-centered Approach. Creative Education (CE), Scientific Research Publishing. 8(6). 953-974. 2151-4755. https://doi.org/10.4236/ce.2017.86070

Nisanholtz-Ganot, R. \& Davidovitch, N. (2018). Evaluation of Teaching and Learning Outcomes in Health Systems Management Studies, the Case of Israel: Ideal versus Actual. In. R. L. Raby \& E. J. Valeau (Eds.), pringer international Handbook of education. Handbook of comparative studies on community colleges and global counterparts. (pp. 381-399). NY: Springer International Publishing. ISBN: 978-3-319-38909-7. https://doi.org/10.1007/978-3-319-50911-2_48

Eckhaus, E. (2016). Corporate transformational leadership's effect on financial performance. Journal of Leadership, Accountability and Ethics, 13(1), 90-102.

Eckhaus, E. (2018). Measurement of organizational happiness. In J. Kantola, T. Barath, \& S. Nazir (Eds.), Advances in Human Factors, Business Management and Leadership. AHFE 2017. Advances in Intelligent Systems and Computing, 594, 266-278). Cham: Springer International Publishing. https://doi.org/10.1007/978-3-319-60372-8_26

Eckhaus, E. (2019). Happiness in Fashion. In J. Kantola, S. Nazir, \& T. Barath (Eds.), Advances in Human Factors, Business Management and Society. AHFE 2018. Advances in Intelligent Systems and Computing, 783, 15-25. Cham: Springer International Publishing. https://doi.org/10.1007/978-3-319-94709-9_2

Eckhaus, E., \& Ben-Hador, B. (2017). Gossip and gender differences: a content analysis approach. Journal of Gender Studies, 1-12. https://doi.org/10.1080/09589236.2017.1411789 
Eckhaus, E., \& Ben-Hador, B. (2018). To gossip or not to gossip: Reactions to a perceived request to gossip - a qualitative study. Trames : A Journal of the Humanities and Social Sciences, 22(3), 273-288. https://doi.org/10.3176/tr.2018.3.04

Eckhaus, E., \& Davidovitch, N. (2018a). Impact of gender and conference size on conference preferences employing natural language processing. International Journal of Educational Methodology, 4(1), 45-52. https://doi.org/10.12973/ijem.4.1.45

Eckhaus, E., \& Davidovitch, N. (2018b). Improving academic conferences - criticism and suggestions utilizing natural language processing. European Journal of Educational Research, 7(3), 445-450. https://doi.org/10.12973/eu-jer.7.3.445

Eckhaus, E., \& Sheaffer, Z. (2018a). Factors affecting willingness to contribute goods and services on social media. The Social Science Journal. https://doi.org/10.1016/j.soscij.2018.08.001

Eckhaus, E., \& Sheaffer, Z. (2018b). Happiness enrichment and sustainable happiness. Applied Research in Quality of Life. https://doi.org/10.1007/s11482-018-9641-0

Eckhaus, E., \& Sheaffer, Z. (2018c). Managerial hubris detection: the case of Enron. Risk Management, 20(4), 304-325. https://doi.org/10.1057/s41283-018-0037-0

Eckhaus, E., Taussig, R., \& Ben-Hador, B. (2018). The effect of top management team's tacit persuasion on the stock market. $e$ - Journal of Social \& Behavioural Research in Business, 9(2), 9-22.

Eckhaus, E., Weber, M., Koppel, M., \& Spiegel, U. (2018). Inequalities among employees with respect to their contributions and rewards. e-Journal of Social \& Behavioural Research in Business, 9(1), 1-9.

Ehie, I. \& Karathanos, D. (1994). Business faculty performance evaluation based on the new AACSB accreditation standards. Journal of Education for $\quad$ Business, $\quad 69(5), \quad 257-\quad 262$. https://doi.org/10.1080/08832323.1994.10117695

Ghasempour, Z., Bakar, M. N., \& Jahanshahloo, G. R. (2014). Mix-method design in educational research: strengths and challenges. International Journal of Pedagogical Innovations, 2(2), 83-90. https://doi.org/10.12785/IJPI/020204

Harrison, P., Douglas, D., \& Burdsal, C. (2004). The relative merits of different types of overall evaluations of teaching effectiveness. Research in Higher Education, 45(3), 311-323. https://doi.org/10.1023/B:RIHE.0000019592.78752.da

Hativa, N. (2002). Contemporary thoughts on university and college teaching: teaching as a profession and as scholarship. Al Hagova, 1, 6-9. [Hebrew]

Hativa, N. (2003a). Are teachers in the humanities and arts better than their colleagues in management and engineering? Al Hagova, 2, 38-40. [Hebrew]

Hativa, N. (2003b). What teachers should know and be able to do - reform in teaching standards. Hed Hachinuch, 6 , 14-19. [Hebrew]

Hativa, N. (2008). Myths and facts about evaluation surveys by students. Al Hagova, 7, 13-14. [Hebrew]

Hativa, N., Many, A., \& Dayagi, R. (2010). The whys and wherefores of teacher evaluation by their students. Al Hagova, 9, 30. [Hebrew]

Hinz, A., Sander, C., Glaesmer, H., Brähler, E., Zenger, M., Hilbert, A., \& Kocalevent, R.-D. (2017). Optimism and pessimism in the general population: Psychometric properties of the Life Orientation Test (LOT-R). International Journal of Clinical and Health Psychology, 17(2), 161-170. https://doi.org/10.1016/j.ijchp.2017.02.003

Hu, L. t., \& Bentler, P. M. (1999). Cutoff criteria for fit indexes in covariance structure analysis: Conventional criteria versus new alternatives. Structural equation modeling: a multidisciplinary journal, 6(1), 1-55. https://doi.org/10.1080/10705519909540118

Iram, Y. (1978). The effect of traditions in higher education on the academic course of the Hebrew University. Iyunim Behinuch, 28, 123-140. [Hebrew]

Kulik, J.A. (2001). Student Ratings: Validity, Utility, and Controversy. New Directions for Institutional Research, (109), 9 - 25. https://doi.org/10.1002/ir.1 
Marsh, H. W. \& Roche, L. A. (1994). The use of students' evaluations of university teaching to improve teaching effectiveness. Final project report for the Evaluations and Investigations Program of the Department of Employment and Education. Canberra: Australian Government Printing Service.

Marsh, H. W. (1987). Students' evaluations of university teaching: Research findings, methodological issues, and directions for future research. International Journal of Educational Research, 11(3), 253-288. https://doi.org/10.1016/0883-0355(87)90001-2

Miller, R. I. (1990). Major American higher education issues and challenges in the 1990s. London: Jessica Kingsley.

Mizrachi, Y. (1994). History of the tension between general liberal higher education and disciplinary specialist higher education and inspecting the option of a balancing curricular program in the regional colleges. School of Educational Leadership, Jerusalem. [Hebrew]

Toosinezhad, Z., Mohamadpoor, M., \& Tabatabaee Malazi, H. (2018). Dynamic windowing mechanism to combine sentiment and $\mathrm{N}$-gram analysis in detecting events from social media. Knowledge and Information Systems. https://doi.org/10.1007/s10115-018-1242-6

Smith, K. \& Pollak, M. W. (2008). What Can They Say about My Teaching? Teacher Educators' Attitudes to Standardised Student Evaluation of Teaching. European Journal of Teacher Education, 31(2), 203-214. https://doi.org/10.1080/02619760802000248

Yaoz, H., \& Iram, Y. (1987). Changes in the curriculum in comparative literature-analysis. Iyunim Behinuch, 46/47, 152-170. [Hebrew] 